\title{
The Population Council's approach: Promoting healthy, safe, and productive transitions to adulthood
}

Population Council

Follow this and additional works at: https://knowledgecommons.popcouncil.org/departments_sbsr-pgy

Part of the Demography, Population, and Ecology Commons, Family, Life Course, and Society Commons, Gender and Sexuality Commons, International Public Health Commons, and the Medicine and Health Commons How does access to this work benefit you? Let us know!

\section{Recommended Citation}

"The Population Council's approach: Promoting healthy, safe, and productive transitions to adulthood," Promoting Healthy, Safe, and Productive Transitions to Adulthood, Overview. New York: Population Council, 2011. 


\section{The challenge}

\section{Adolescence is a critical phase of human devel- opment during which the stage is set for adult life.}

$\mathrm{M}$

ore than 1.5 billion

people aged 10-24 in

developing countries

are transitioning from childhood

to the roles and responsibilities of

adulthood-as workers, citizens,

spouses, and parents-during

a period of unprecedented

global change. Subsequent

generations of young people

will be even larger. Without

adequate investments in their

health and education as well as

in opportunities for productive

livelihoods, young people's future prospects will be limited. Special challenges face young people in Africa, where half of all new HIV infections occur in persons aged 15-24 and where young women are a majority of those infected. Many nations' futures, as well as the achievement of many of the UN Millennium Development Goals, depend on how well adolescents navigate this phase of their lifecycle.

\title{
The Population Council's approach
}

\author{
The Population Council's \\ intensified focus on \\ adolescents began in the \\ early 1990s, accompanied \\ by a commitment to move \\ the field of adolescent \\ research and programs \\ from one often narrowly \\ focused on sexuality, \\ reproductive health, and
}

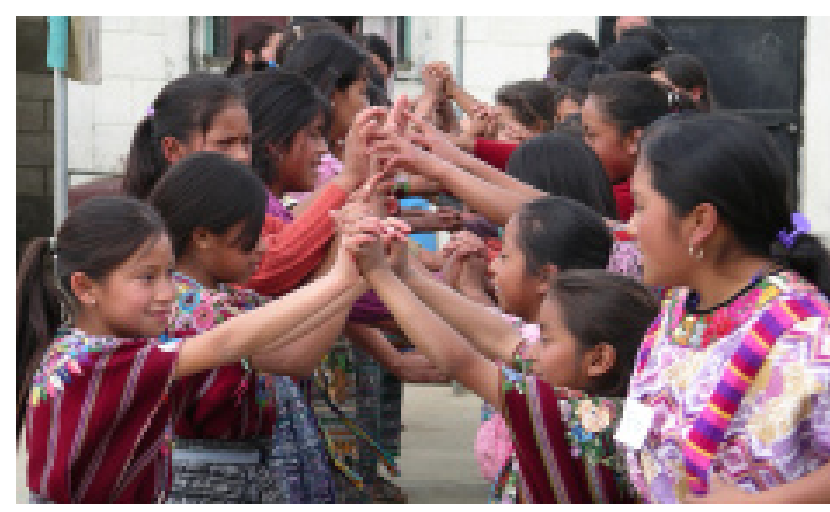

Abriendo Oportunidades creates safe spaces and provides mentors for Mayan girls.

behavior to the broader social and economic issues that underpin adolescent health and well-being.

In 1998, with the publication of The Uncharted Passage - a benchmark review of the situation of adolescent girls in developing countries-the current program of work was launched. The Council's approach has been characterized by four hallmarks:

- Consistent attention to the implications of gender during adolescence, in particular the needs of girls in the least developed countries. In these settings, girls' opportunities are often limited, they frequently experience gender-based violence, they may be at risk for child marriage, and they are disproportionately affected by the HIV epidemic.

- A multisectoral approach, which engages facets of society that influence the lives of adolescent girls: families and community leaders; boys and men; nongovernmental and community-based organizations; and the health and education sectors. Poor health in adolescence does not arise from physiological factors alone, but is also determined by young people's-particularly girls'-social isolation and economic vulnerability;

- A special concern with inequality-based on gender, social and economic class, urban/ rural residence, and access to the modern economy-which intensifies during adolescence;

- A commitment to evidence-based policy research combined with program development and evaluation, ensuring that the fruits of policy analysis will be rapidly applied to on-the-ground programs and policies. 


\section{Theory of Change}

The Council's theory of change asserts that the foundation of productive lives-which may involve marriage, first birth, employment, citizenship, and economic sufficiency-is formed during adolescence. The building blocks of this foundation include lifeskills, financial literacy, sexual and reproductive health, negotiation skills, and literacy. This is also the period during which poverty may be consolidated or conquered and often when gender-based violence is first encountered. Thus our focus is on building adolescent social and economic assets among the most vulnerable populations, to ensure safe and productive transitions to these adult roles. Assets are acquired and cannot be taken away from a young person; while the benefits of these assets may not be fully realized until adulthood (often years later), intermediate outcomes can be assessed.

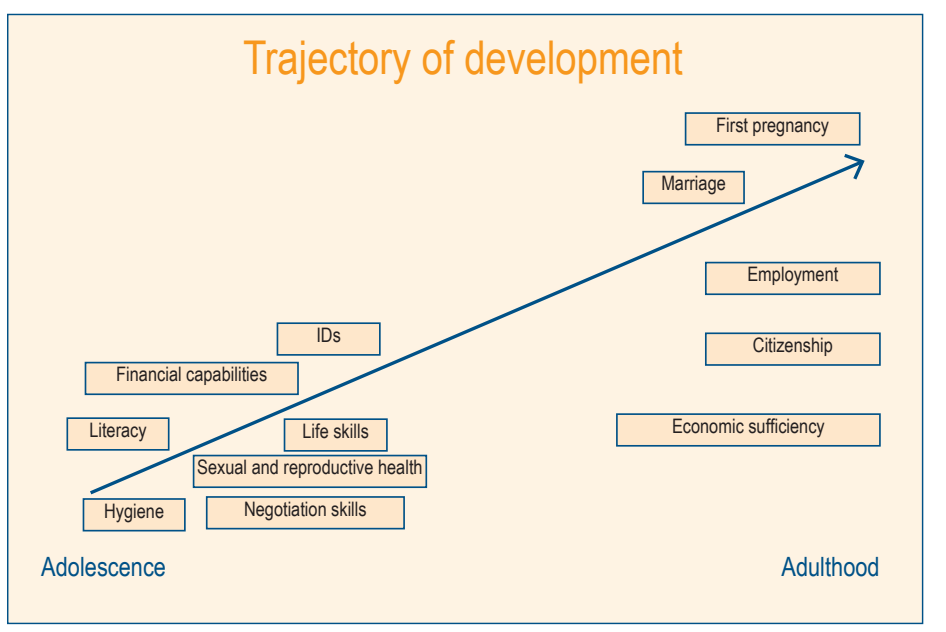

\section{Strategy}

The Council uses data to better understand the diversity of adolescent lives and experiences and to identify the most vulnerable and underserved adolescents. It then works with local partners to develop programs that build the assets of these adolescents, measures changes that occur at the individual and community level, and facilitates the scale-up of successful strategies. Along the way, tools are developed for research and programs that can be shared with the field. Engagement with policymakers-at the community, national, and international levels-permeates the work at each stage, ensuring that policies are developed to address the needs and experiences of this critical cohort of the population.

\section{Collecting, analyzing, and disseminating evidence on the diversity of adolescent lives and experiences}

The Council has made it a priority to mine existing data and collect new data to illuminate the distinctive influences of age, gender, schooling, marital status, living arrangements, and urban/rural residence on the adolescent experience.

Secondary analysis of the household rosters of the Demographic and Health Surveys provide basic information on adolescents residing in those households. This information is summarized in 55 country-specific guides created by the Population Council: The Adolescent Experience In-depth: Using Data to Identify and Reach the Most Vulnerable Young People. The purpose of this series is to provide decisionmakers at all levels-from governments, nongovernmental organizations (NGOs), and advocacy groups - with data on the situation of adolescent girls and boys and young women. The age range covered is 10-24 years. The data are presented in graphs, tables, and maps (wherever possible), providing multiple formats to make the information accessible to a range of audiences (TA\#10).

Nationally and sub-nationally representative surveys. Existing data rarely provide the in-depth information that is gained by interviewing adolescents themselves. The Council has implemented surveys throughout the world to gain insights into the lives of adolescents. National surveys were conducted in Bangladesh, Egypt, Ethiopia, India, and Pakistan, while longitudinal surveys carried out in Malawi and South Africa provide the unique opportunity to follow adolescents over time.

Presenting data in user-friendly ways. A large amount of data that are collected in the world is never analyzed. Even the data that are analyzed is often presented in a way that can only be interpreted by professional statisticians. The Council strives to make data accessible to a variety of audiences for program planning, implementation, and evaluation as well as policy analysis. In addition to creating maps from statistics, we are increasingly using mapping as a participatory exercise in which adolescents in local communities map and describe the context of their lives, define problems, offer coping mechanisms, and devise strategies for development (TA\#30).

\section{Creating innovative tools for the field}

In its data analysis and program implementation, the Council creates innovative resources and tools for others to use. An important tool for gathering information from adolescents on sensitive topics has been the audio computer-assisted self-interview (ACASI). The Council developed its own software for this tool, further enhancing the ability to ensure standardization, confidentiality, linguistic flexibility, and security in data collection.

Our wide-ranging work in program design and interventions have resulted in two core resources:

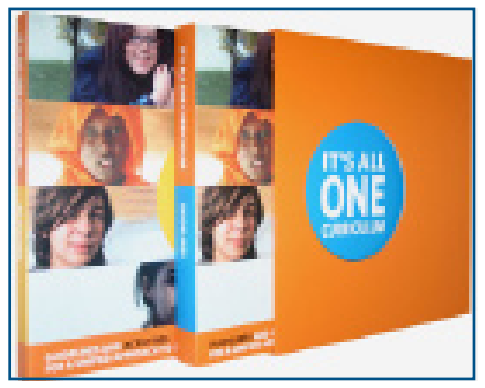

It's All One Curriculum, a twovolume curriculum that places gender issues and human rights at the heart of sex and HIV education, along with 54 activities that engage young people and foster critical thinking skills. Available in English, Spanish, and French. www.itsallone.org 


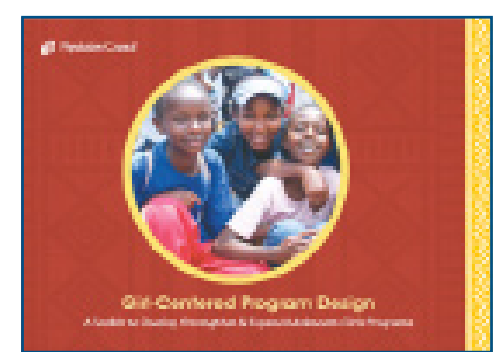

Girl-Centered Program

Design: A Toolkit to Develop,

Strengthen, and Expand

Adolescent Girls Programs. This

toolkit focuses on the structure,

content, and evaluation of pro-

grams for girls. It is a practical tool

for starting or strengthening girls'

programs and is available in English, Spanish, and French.

www.popcouncil.org/publications/books/2010_AdolGirlsToolkit.asp

\section{Using safe spaces to build assets for a healthy and productive adulthood}

The limited reach and coverage of existing youth programs and their focus on health information and services have not sufficiently addressed the needs of many adolescents. These young people may be out of school, away from home, married, or trapped in a cycle of exploitative work and poverty. The Population Council concentrated its initial efforts on building assets for adolescent girls, who face disproportionate risks. Experimental interventions were designed with local partners to offer adolescent girls protected gathering places. In these "safe spaces," girls develop healthy relationships with peers and mentors, gain confidence, acquire knowledge, and learn new skills.

\section{Lessons Learned}

\section{Whom do we reach?}

The Council's interventions have demonstrated that it is possible to reach vulnerable adolescents who have previously been untouched by youth investments. Through targeted recruitment strategies, these interventions have identified and recruited target populations.

- Girls at risk for early marriage are often removed from the public eye, but they were recruited into culturally acceptable interventions in Bangladesh, Burkina Faso, Egypt, Ethiopia, Guatemala, India, and Kenya with evidence that age at marriage was significantly delayed as a result (TA\#13; 9; 12; 20; 5; 2; 19; 29).

- Married girls are among the most difficult adolescents to reach. Following marriage, a girl often moves into the family home of her husband, a place where she has very limited social connections and with a man who is often much older than she. Projects in Burkina Faso, Ethiopia, and India brought these girls out of the shadows, linking them to one another for social support, and providing access to services (TA\#9; 20; 8). The First Time Parents project in India engaged both partners and focused on the positive aspects of being new parents by reevaluating gender roles and expectations around childcare, cooking, fetching water, etc.

- Domestic workers in poor urban households experience dire working conditions, with little to no pay, grueling hours, and frequent sexual abuse. In Ethiopia, where many girls arrive in Addis after fleeing early marriage in the rural areas, domestic workers were identified in a house-by-house recruitment strategy. Negotiations with employers resulted in the creation of a safe spaces program, Biruh Tesfa (TA\#21); using a government building in the slums of Addis, girls aged 10-19 meet each week with mentors to gain social and economic assets to rebuild their lives.

- Young adolescents. The first wave of interventions targeted girls who were aged 15 and older. But it quickly became clear that it was necessary to intervene well before girls encountered certain events (child marriage, school-leaving, first sex, etc). Increasingly, projects are reaching girls aged $10-14$ years.

- Girls at risk of HIV infection. Adolescent girls continue to bear the brunt of HIV infections. Safe spaces programs build positive peer relationships, negotiating skills, and economic assets that can help girls avoid unwanted and/or risky behaviors.

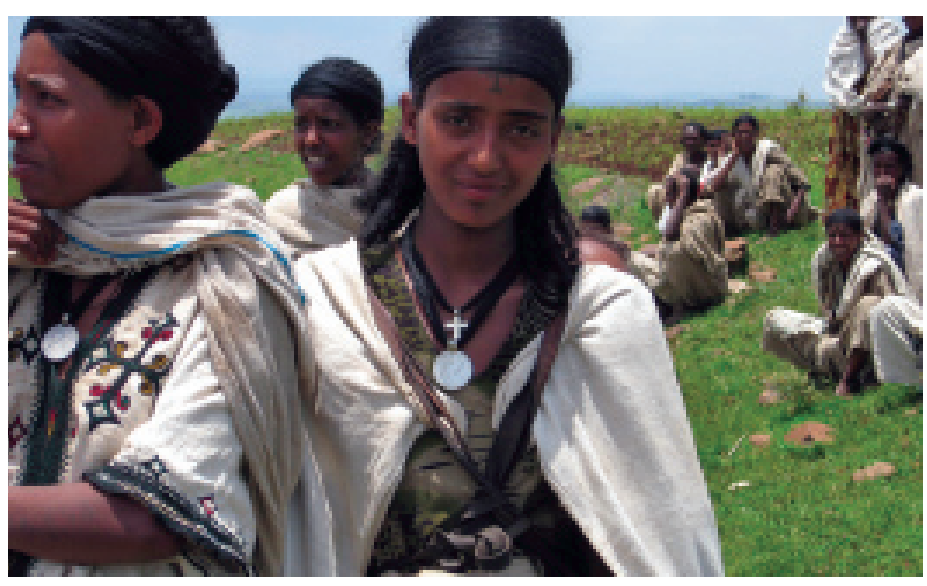

Berhane Hewane in Amhara, Ethiopia seeks to prevent child marriage.

\section{What do we provide?}

In addition to the social assets created in safe spaces, many interventions focus on building financial capabilities, savings, livelihoods opportunities, and sexual and reproductive health:

- Siyakha Nentsha in South Africa takes advantage of the high rates of school enrollment in KwaZulu Natal and works with 1100 girls and boys in their schools. One component of the program is financial literacy, and the curriculum has been certified by the government so that completing the program provides a marketable credential for young people (TA\#4).

- Working through adolescent clubs in rural areas and non-formal technical schools in urban areas, the Kishori Abhijan program in Bangladesh reaches girls aged 15 to 19 to promote financial education through mentoring relationships. We are assessing the value of adding mentoring to traditional financial educational approaches (TA $\# 13)$.

- Safe and Smart Savings is an extension of one of the earliest safe spaces programs in Kenya, Binti Pamoja. Located in the slum of Kibera, the program goes beyond financial education to an actual banking program in partnership with two banks in Nairobi. The program is now being extended to Uganda. Currently reaching 2300 young people, the full roll out phase will reach upwards of 20,000 (TA\#29). 


\section{How do these programs link to other services?}

The interventions do not deliver health services directly, but rather link participants to existing services in the community through exposure visits, formal collaborations, and awareness-raising.

- Livelihoods/savings. In Kenya, the program partners with commercial banks to ensure that girls gain access to private sector financial services (TA\#29); In South Africa, the curriculum builds awareness of government financial assistance programs for which many adolescents qualify, but few know how to access.

- Education. The Ishraq program in Egypt is a "second chance" program whose objective is to reach girls who have left school and mainstream them into government schools at the end of the program. At the end of the pilot project, $92 \%$ of the girls who sat for the exam passed and enrolled in formal schooling (TA\#12).

- Gender-based violence services. While not developed as GBV programs from the onset, mentors in safe space programs observed that the issue of violence emerged as a major theme across all the intervention sites. The girls-only spaces became a safe place to engage in these discussions, learn about their rights, and share coping strategies. The programs are continually evolving as venues for violence prevention.

\section{Can these programs be taken to scale?}

The expansion of a program is largely dependent upon the existence of a government, NGO, or faith- and community-based organizations with the capacity to implement the program within a broad population. The model for this scale-up differs dramatically across contexts, but common features include 1) early engagement with potential scale-up partners, and 2) attention to the cost and streamlining of the program.

- The Biruh Tesfa project in the slums of Ethiopia partnered with the government from the inception of the program. Working from community halls donated by the kebele, or local government, the program now reaches 16,500 out-of-school girls and is currently expanding to 12 additional cities to reach another 30,000 girls. Salaries for mentors were also pegged at the level of a government social worker, ensuring the possibility of scale-up through government resources (TA\#21).

- In rural Upper Egypt, the Ishraq program works with 1800 girls ages 12 to 15 to encourage school attendance and increase health literacy. Having gained strong community and government support for the program, it is now in an expansion stage and is expected to become a government-sponsored program in the near future (TA\#12).
- The Abriendo Oportunidades program in Guatemala reaches 1260 rural Mayan girls aged 8 to 18. The programs are based in community halls and schools and employ a "cascading mentorship" model so that girls may advance into positions of leadership in the program. Local governments, as well as NGOs and the private commercial sector, are increasingly engaged, providing the necessary anchors for sustainability and institutionalization. In addition to the expansion of the program itself, the Abriendo model is being adopted and replicated by public, NGO, and private-sector partners in Guatemala, and is poised to become the first national program for indigenous girls in the region (TA\#5).

- The Siyakha Nentsha program in South African schools is already an accredited curriculum and the Ministry of Education is eager to expand the program across KwaZulu Natal and beyond (TA\#4).

- The Berhane Hewan program in rural Ethiopia has reached 12,000 married and unmarried girls aged 10 to 19 in a region where half of girls are married by the age of 15 . The kebele structures in villages provide the venue and with government support the program will reach 72,000 girls ( $T A \# 20$ ).

- The Kishori Abhijan program aims to reduce school dropout rates, increase girls' independent economic activity, and raise the age at which girls marry. A joint effort by the Population Council, UNICEF, UNFPA, the Bangladesh Institute of Development Studies (BIDS), the Bangladesh Rural Advancement Committee (BRAC), and the Centre for Mass Education in Science (CMES), the program combines life-skills and livelihoods training with BRAC and CMES, large and well-known NGOs that have implemented the program in 14 rural districts enrolling 15,000 girls aged 13-22. Based on a successful pilot evaluated by Population Council and BIDS, the life-skills component is being scaled up through BRAC and CMES to enroll more than 250,000 girls in 58 districts (TA\#13).

\section{What's next?}

The next stage of this work is to demonstrate empirically how investments in critical life skills and assets during adolescence affect later outcomes. We propose doing this by tracking participants over time in at least two current projects and incorporating a longitudinal approach to new projects. Recognizing that individual-level asset development must take place in the context of a favorable environment, the new projects will also give greater attention to boys and men, with a focus on a community approach to the prevention of gender-based violence.

\section{Population Council}

The Population Council changes the way the world thinks about critical health and development issues. We seek to understand the causes and consequences of gender inequality and the disparities in opportunity that arise during adolescence. We provide the evidence for better on-theground programs and policies that ensure successful and productive transitions to adulthood in developing countries. www.popcouncil.org

○ 2011 The Population Council, Inc.

4 - Visit www.popcouncil.org/publications/serialsbriefs/TABriefs.asp for all briefs in the Promoting healthy, safe, and productive transitions to adulthood series. 